for the more dependent elderly functionally mentally ill. Experience of the fate of elderly psychiatric hospital residents discharged into nursing homes in the United States has been highly problematic (Brown, 1985; Linn et al, 1985). Although it has been argued that comparisons between the private sectors in the USA and Britain are misleading (Perkins et al, 1989), the current British government strategy which specifically encourages a "mixed economy of care" must be a cause for concern.

It is possible that the need for specialised public sector provision for elderly people suffering from a functional mental illness may be recognised, and that the necessary capital and revenue support will be forthcoming. If services for the patients with longterm and severe disabilities are not made available, the hospital closure programme can only progress by the collapsing of hospitals onto residual institutions. Such a strategy may be appropriate for some institutionalised patients. However, this hardly meets aspirations for the development of comprehensive local mental health services, which will come under increasing strain without adequate provision for those who require long-term highly supported residential care.

\section{Acknowledgements}

The assessments were carried out by Sally Mill, Kath Siddle and Colin Wilson. Dr Adrienne Little, Principal Psychologist for the Elderly, suggested the use of the CAPE as an assessment tool.

\section{References}

Brown, P. (1985) The Transfer of Care. Psychiatric Deinstitutionalisation and its Aftermath. London: Routledge.

Holloway, F., Booker, D., Mill, S. et al (1988) Progress and pitfalls in the move out of hospital. The Health Service Journal, 11 August, 910-912.

LiNN, M. W., GUREL, L., Williford, W. O. et al (1985) Nursing home care as an alternative to psychiatric hospitalisation. Archives of General Psychiatry, 42, 544-551.

Perkins, R. E., King, S. \& Hollyman, J. A. (1989) Resettlement of old long-stay psychiatric patients: the use of the private sector. British Journal of Psychiatry. 155, 233-238.

WeBB, Y. \& CLIFFoRd, P. (1988) Warley Hospital: patient needs survey. London: NUPRD.

A full list of references is available on request to the author.

\title{
Regional Meeting of the College in Bahrain
}

Members and Fellows are reminded that the Regional Meeting of the College in Bahrain was postponed from October 1990 until 28-30 October 1991. The full programme extends from Saturday, 26 October to Sunday, 3 November and includes flights and accommodation in both Cairo and Bahrain. The organisers will be in touch with all participants who registered for the original meeting. Anyone interested in attending who did not register for the original meeting should contact either $\mathrm{Dr} \mathbf{M}$. A. Mawgoud, Severalls Hospital, Boxted Road, Colchester CO4 5HG or Dr Charlotte Kamel, Ministry of Health, PO Box 12, Bahrain. These dates are provisional and are yet to be confirmed by the College. 